\title{
1 Spatial and developmental heterogeneity of calcium signaling in olfactory
}

\section{2 ensheathing cells}

3 Anne Thyssen ${ }^{1}$, Maren Stavermann ${ }^{1,2,3}$, Kristina Buddrus ${ }^{3}$, Michael Doengi ${ }^{1}$, Jenny A.

4 Ekberg ${ }^{4}$, James A. St John ${ }^{4}$, Joachim W. Deitmer ${ }^{1,2}$, Christian Lohr ${ }^{1,2,3}$

$5{ }^{1}$ Abteilung für Allgemeine Zoologie and ${ }^{2}$ Graduate Training Group 845, TU Kaiserslautern,

6 Postfach 3049, 67653 Kaiserslautern, Germany

$7{ }^{3}$ Biozentrum Grindel, Universität Hamburg Martin-Luther-King-Pl. 3, 20146 Hamburg,

8 Germany

$9{ }^{4}$ National Centre for Adult Stem Cell Research, Eskitis Institute for Cell and Molecular

10 Therapies, Griffith University, Nathan 4111, Brisbane, QLD, Australia

Running title: Calcium signaling in olfactory ensheathing cells

13

14

15

16

17

24

Word count: Abstract: 248

Introduction: 459

Materials and Methods: 1106

Results: 2125

Discussion: 1262

References: 1350

Figure Legends: 888

Correspondence to: Christian Lohr, christian.lohr@uni-hamburg.de

Keywords: Olfactory bulb, olfactory nerve layer, development, metabotropic glutamate receptor, purinergic signaling, 


\section{Abstract}

2 Olfactory ensheathing cells (OECs) are specialized glial cells in the mammalian olfactory 3 system supporting growth of axons from the olfactory epithelium into the olfactory bulb.

4 OECs in the olfactory bulb can be subdivided into OECs of the outer nerve layer and the inner

5 nerve layer according to the expression of marker proteins and their location in the nerve

6 layer. In the present study, we have used confocal calcium imaging of OECs in acute mouse

7 brain slices and olfactory bulbs in toto to investigate physiological differences between OEC

8 subpopulations. OECs in the outer nerve layer, but not the inner nerve layer, responded to

9 glutamate, ATP, serotonin, dopamine, carbachol and phenylephrine with increases in the 10 cytosolic calcium concentration. The calcium responses consisted of a transient and a tonic 11 component, the latter being mediated by store-operated calcium entry. Calcium measurements 12 in OECs during the first three postnatal weeks revealed a down-regulation of $\mathrm{mGluR}_{1}$ and $13 \mathrm{P}_{2} \mathrm{Y}_{1}$ receptor-mediated calcium signaling within the first two weeks, suggesting that the 14 expression of these receptors is developmentally controlled. In addition, electrical stimulation 15 of sensory axons evoked calcium signaling via $\mathrm{mGluR}_{1}$ and $\mathrm{P}_{2} \mathrm{Y}_{1}$ only in outer nerve layer 16 OECs. Down-regulation of the receptor-mediated calcium responses in postnatal animals is 17 reflected by a decrease in amplitude of stimulation-evoked calcium transients in OECs from 18 postnatal day 3 to 21 . In summary, the results presented reveal striking differences in the development of receptor responses during development and in axon-OEC communication between the two subpopulations of OECs in the olfactory bulb. 


\section{Introduction}

2 Assembling neuronal networks by axonal wiring and formation of synapses during

3 development requires coordinated interaction between cells and tissues. In the olfactory

4 system, a lifelong integration of new neurons into established networks persists due to

5 continuous neuronal turnover, making it a valuable model to study basic principles of cell-cell

6 interaction during development and regeneration. A specialized glial cell type, the olfactory

7 ensheathing cell (OEC), is of particular interest with respect to the regenerative capability of

8 the olfactory system, since it has been shown to enhance axon growth and is involved in the

9 guidance of growing axons from the olfactory nerve, where OECs ensheath fascicles of axons

10 of olfactory receptor neurons (ORNs), into the olfactory bulb (Doucette, 1990). OECs

11 perform their growth-promoting properties not only in the olfactory system, but also after

12 transplantation into injured dorsal root ganglia and spinal cord (Ramon-Cueto \& Nieto-

13 Sampedro 1994, Li et al., 1997), making them a potential tool in the therapy of spinal cord

14 lesions (Raisman \& Li, 2007; Barnett and Riddell, 2007). Still enigmatic is the molecular and

15 physiological background of how OECs perform such regenerative tasks.

16 Intracellular calcium signaling in OECs is supposed to play a key role in intercellular

17 signaling pathways between OECs and growing axons in vitro (Hayat et al., 2003). We have

18 recently shown that in the developing olfactory bulb, calcium signaling in OECs can be

19 evoked by stimulation of olfactory receptor axons in situ, which results in vesicular release of

20 glutamate and ATP from the stimulated axons (Rieger et al., 2007; Thyssen et al., 2010).

21 However, other neurotransmitters such as acetylcholine, dopamine and serotonin have been

22 shown to be released from local and centrifugal neurons in the olfactory bulb (Fletcher and

23 Chen, 2010). Therefore, we asked whether OECs are able to respond to neurotransmitters

24 other than glutamate and ATP. Since the presence of at least two different subpopulations of

25 OECs have been demonstrated in the rodent olfactory nerve layer by means of marker protein

26 expression, namely OECs of the outer part and OECs of the inner part of the nerve layer (Au John Wiley ${ }^{3} \&$ Sons, Inc. 
1 et al., 2002), we have focussed on studying differences in calcium signaling between these

2 two cell populations. We also followed changes in glutamate- and ATP-dependent calcium

3 signaling during the first three postnatal weeks, a time range in which the olfactory system

4 matures with respect to its morphology and functioning. The results of our study indicate that

5 only OECs of the outer nerve layer, but not of the inner nerve layer, respond to

6 neurotransmitters such as glutamate, ATP, dopamine, acetylcholine and serotonin. Glutamate-

7 and ATP-induced calcium signaling was most prominent in the first postnatal week and

8 decreased thereafter, suggesting a particular role of these responses for the early development

9 of the olfactory epithelium to olfactory bulb pathway.

\section{Materials and Methods}

Preparation of olfactory bulb slices and olfactory bulbs in toto

NMRI mice of both genders at postnatal day (P) 0-20 were obtained from the animal facilities of the universities of Kaiserslautern and Hamburg. Animals were decapitated in accordance with the EU animal welfare guidelines. The skull was opened along the mid-sagittal line and bone hemispheres removed laterally. The olfactory bulbs were removed and glued to the stage of a vibroslicer (Leica VT1000). Sagittal slices of $250 \mu \mathrm{m}$ thickness were cut in chilled preparation solution (in mM: $130 \mathrm{NaCl}, 2.5 \mathrm{KCl}, 26 \mathrm{NaHCO}_{3}, 25$ glucose, $1.1 \mathrm{NaH}_{2} \mathrm{PO}_{4}, 2.5$ $\mathrm{MgCl}_{2}, 0.5 \mathrm{CaCl}_{2}$,) and kept afterwards for $1 \mathrm{~h}$ at $30{ }^{\circ} \mathrm{C}$ in preparation solution gassed with carbogen $\left(95 \% \mathrm{O}_{2}, 5 \% \mathrm{CO}_{2}\right)$. Bulk loading with the calcium-sensitive dye Fluo-4 was performed by the AM-ester derivative ( $2 \mu \mathrm{M}$ for $1 \mathrm{~h}$ at room temperature). Slices were placed in a recording chamber, fixed with a platinum grid and perfused continuously with gassed artificial cerebrospinal fluid (ACSF, $130 \mathrm{NaCl}, 5 \mathrm{KCl}, 25 \mathrm{NaHCO}_{3}, 25$ glucose, $10 \mathrm{NaH}_{2} \mathrm{PO}_{4}$, $2 \mathrm{MgCl}_{2}, 1 \mathrm{CaCl}_{2}, 0.05 \mathrm{Na}$-L-Lactate). In calcium-free solution, $\mathrm{CaCl}_{2}$ was replaced by $\mathrm{MgCl}_{2}$, and residual calcium was buffered by addition of $1 \mathrm{mM}$ EGTA. 
1 In-toto preparations of olfactory bulbs were prepared as described before (Stavermann et al.,

2 2012). Olfactory bulbs were removed from the opened cranium, glued onto a small coverslip

3 and placed in a perfusion chamber. Fluo-4 AM $(200 \mu \mathrm{M})$ was filled into a micropipette pulled

4 with a patch-pipette puller (Sutter Instruments, Novato, CA, USA), the pipette was inserted

5 into the nerve layer and Fluo-4 AM was injected into the tissue with pressure ( 0.7 bar) for 10

6 s. Fluo-4 was allowed to diffuse into the cells for $30 \mathrm{~min}$.

\section{Cultured OECS}

9 Purified cultures of OECs were generated from 7-day old S100ß-DsRed mice (Windus et al, 2007). In these mice OECs express DsRed fluorescent protein and are easily visualized in

11 culture using fluorescent microscopy. To obtain OECs, the olfactory bulbs were removed

12 from the cranial cavity and the nerve fibre layer from the entire bulb was dissected out. The

13 NFL tissue was incubated in plastic 24-well plates coated with Matrigel basement membrane

14 matrix (10 mg/ml; BD Biosciences, San Jose, CA) and maintained in Dulbecco's Modified

15 Eagle Medium containing 10\% fetal bovine serum, G5 supplement (Gibco), gentamicin

16 (Gibco, $50 \mathrm{mg} / \mathrm{ml}$ ) and L-glutamine $(200 \mu \mathrm{M})$ at $37^{\circ} \mathrm{C}$ with $5 \% \mathrm{CO}_{2}$ for $3-5$ days.

17 Contaminating macrophages were removed by incubation with TrypLE Express (Gibco) for 2

18 min. OECs were incubated with TrypLE Express for a further 4-5 min and then replated in the

19 same medium. These cultures routinely give purity of $\sim 90 \%$ OECs which have previously

20 been shown to be immunoreactive for S100ß and p75NTR which are markers of OECs

21 (Windus et al., 2007, Windus et al., 2010). For $\mathrm{Ca}^{2+}$-imaging, cells on cover slips were stained 22 with $1.5 \mu \mathrm{M}$ Fluo4-AM (30 min) in an incubator at $37^{\circ} \mathrm{C}$ in a $5 \%$ humidified atmosphere, 23 transferred into a perfusion chamber and continuously superfused with $\mathrm{CO}_{2}$-independent 24 medium (1x, Gibco, Invitrogen Corp, Melbourne, Australia). Time series were acquired using 25 a Zeiss Axioobserver Z1 microscope with a CCD camera (AxioCam MRm, Zeiss, Goettingen, 26 Germany) at a frequency of $0.2 \mathrm{~Hz}$. Images were compiled using Zeiss Axiovision Rel 4.6.3. 
2 Drugs

3 All drugs were dissolved directly before use in ACSF. Glutamate, serotonin, carbachol,

4 dopamine, phenylephrine, adenosine, ATP, 2MeSATP, $\gamma$-S-ATP, UTP, UDP, and IDP were

5 obtained from Sigma-Aldrich (Germany). CHPG, DHPG, CPCCOEt, cyclopiazonic acid, and

6 YM298198 were obtained from Ascent Scientific (Bristol, UK). JNJ16259685, MRS2179,

7 and PPADS were obtained from Tocris (Bristol, UK). ARC69931MX was a gift from the

8 Medicines Company (Waltham, MA, USA). All drugs were applied to the preparation via the

9 perfusion system.

11 Calcium Imaging

12 Fluo-4-loaded cells were imaged using confocal microscopy (Zeiss LSM 510 for brain slices,

13 Nikon eC1 for in-toto preparations). Time series of images (512x512 pixel) were acquired at a

14 rate of one frame every 3 seconds. Regions of interest covering single glial cell somata were

15 defined, and changes in calcium were analysed throughout the experiment as changes in

16 fluorescence $(\Delta \mathrm{F})$ with respect to the resting fluorescence, which was set to $100 \%$.

17 Quantification of the calcium transients was achieved by calculating the amplitude of $\Delta \mathrm{F}$,

18 except for quantification of store-operated calcium entry, which is reflected by a sustained

19 fluorescence increase, and was therefore measured as the area under the response curve

20 normalized to the peak amplitude. All values are given as mean values \pm standard error of

21 the mean with $n$ giving the number of cells investigated. Statistical differences between means

22 were evaluated using Student's t-test at an error probability of $\mathrm{p}<0.05$.

\section{Immunohistochemistry}

25 Sagittal olfactory bulb slices of $250 \mu \mathrm{m}$ thickness were fixed for $1 \mathrm{~h}$ in $4 \%$ formalin solution, 26 afterwards washed 3 times carefully in phosphate buffered solution (PBS) for 5 min and then John Wiley ${ }^{6}$ Sons, Inc. 
1 incubated in citrate buffer (10 mM citric acid, $0.05 \%$ Tween $20, \mathrm{pH} 6.0)$ for $20 \mathrm{~min}$ at $90^{\circ} \mathrm{C}$.

2 Preincubation in blocking solution (3\% BSA, 10\% NGS, 0.15 Triton X-100) for $2 \mathrm{~h}$ was

3 followed by incubation with the primary antibody (mouse anti-mGluR $\mathrm{R}_{1}$, BD Bioscience,

4 1:500; rabbit anti-S100, Dako, 1:1000; rabbit anti-P75NTR, Chemicon, 1:200) in PBS

5 containing $3 \%$ BSA overnight at $4{ }^{\circ} \mathrm{C}$. The next day, slices were washed 3 times in PBS for 5

$6 \mathrm{~min}$ and then incubated for $2 \mathrm{~h}$ at room temperature with the secondary antibody (goat anti

7 mouse-IgG and goat anti rabbit-IgG coupled with Alexa 488 and Alexa 543, respectively) in

8 PBS containing $10 \mu \mathrm{M}$ propidium iodide. After a final washing step in PBS (3 times 5 min),

9 slices were mounted on object slides with self-hardening embedding medium (glycerol 40\%,

10 polyvinyl alcohol $16 \%$, phenol $0,7 \%$, Tris $0.05 \mathrm{mM}$ ). Slices of the olfactory bulb were

11 scanned with a Zeiss LSM 510 at a resolution of $2048 \times 2048$ pixels using excitation

12 wavelengths of $488 \mathrm{~nm}$ (Alexa 488 and DiA, argon laser) and $534 \mathrm{~nm}$ (propidium iodide,

13 helium-neon laser) sequentially. Emission wavelengths were separated by a band pass filter

$14(510-560 \mathrm{~nm})$ and a long pass filter $(>560 \mathrm{~nm})$. Axons were traced with DiA as described

15 before (Rieger et al., 2007). In brief, olfactory bulbs were dissected with olfactory epithelia

16 attached, and DiA-coated insect pins were inserted into the epithelium. Specimens were

17 stored for up to 2 months in $2 \%$ PFA to allow for dye diffusion along the receptor axons.

18 After that, the bulbs were cut into $250 \mu \mathrm{m}$ thick slices and analyzed by confocal microscopy.

19 Image stacks of DiA- or antibody-labelled slices were recorded with an axial interval (Z-step)

20 of $0.5 \mu \mathrm{m}$, and projections were rendered over a Z-range of 3-5 $\mu \mathrm{m}$. Control staining without

21 primary antibodies resulted in specimens without significant immunoreactivity, indicating the

22 specificity of the secondary antibodies (not shown). 


\section{$1 \quad$ Results}

2 Histological discrimination of two subpopulations of olfactory ensheathing cells

3 The nerve layer is the most superficial layer of the olfactory bulb and is clearly

4 distinguishable from the glomerular layer by the lack of glomeruli (Fig. 1A-C). OECs in the

5 nerve layer express the calcium-binding protein S100B, and therefore, S100B can be used as

6 specific marker in young animals in which astrocytes are immature and express too low

7 amounts of S100B to be clearly visible by antibody staining (Raponi et al., 2007; Fig. 1A). In

8 the innermost part of the nerve layer, OECs are only weakly S100B-immunopositive, but can

9 be identified as OECs because they strongly express DsRed under the control of the S100B

10 promoter (Fig. 1A, Windus et al., 2010). Another marker of OECs, the P75 neurotrophin

11 receptor, is highly expressed in OECs of the outer nerve layer (Au et al., 2002; Fig. 1B), but

12 only weakly in OECs of the inner nerve layer, suggesting different subpopulations of OECs.

13 Bundles of olfactory receptor axons enter the outer nerve layer where they sort out before

14 crossing into the inner nerve layer where they intermingle with similar odorant receptor axons

15 and enter glomeruli. This suggests that OECs of the outer nerve layer and OECs in the inner

16 nerve layer interact differently with axons (Fig. 1C).

17 To test whether these morphological and histological differences between OEC

18 subpopulations are accompanied by physiological differences, we loaded the calcium

19 indicator Fluo-4 into OECs of brain slices for cytosolic calcium signal recording. The nerve

20 layer consists mainly of olfactory receptor axons with OECs as the major source of cell

21 bodies and is identified by the lack of glomeruli. Strikingly, OECs were preferentially loaded

22 with Fluo-4 and thereby highlighted in the confocal image (Fig. 1D), while receptor axons do

23 not take up Fluo-4 (see also Rieger et al., 2007). Fluo-4 did not label the OECs

24 homogeneously, but stained OECs in the outer nerve layer significantly brighter than in the

25 inner nerve layer (Fig. 1D). 


\section{$1 \quad$ Physiological differences between OEC subpopulations}

2 We have recently shown that olfactory receptor axons release glutamate and ATP, which

3 stimulates calcium signaling in OECs in the nerve layer via mGluR and P2Y receptors

4 (Rieger et al., 2007; Thyssen et al., 2010). In the present study, we compared

5 neurotransmitter-evoked calcium signaling in OECs of the outer and inner nerve layer. Bath

6 application of the mGluR $_{1 / 5}$-selective agonist DHPG $(100 \mu \mathrm{M})$ resulted in calcium transients

7 in OECs of the outer nerve layer, whereas OECs of the inner nerve layer did not respond to

8 DHPG with calcium signaling (Fig. 2A), although in principle, OECs in the inner nerve layer

9 were able to respond to $\mathrm{InsP}_{3}$ receptor activation with calcium transients (Supplementary Fig.

10 1; Stavermann et al., 2012). To further analyze the pharmacological identity of the mGluR in

11 outer OECs, we applied the mGluR $_{5}$-selective agonist CHPG $(100 \mu \mathrm{M})$, which did not evoke

12 calcium signaling in either outer or inner OECs, suggesting the functional expression of

$13 \mathrm{mGluR}_{1}$ in outer OECs. This was confirmed by the efficient inhibition of DHPG-evoked

14 calcium signaling by the mGluR $_{1}$-selective antagonists JNJ16259685, CPCCOEt (Fig. 2B, C),

15 YM298198, as well as by MCPG, a broad spectrum mGluR antagonist (Fig. 2 F). DHPG-

16 evoked calcium transients were reduced by JNJ16259685 to $24.5 \pm 3.7 \%$, by YM298198 to

$1720.0 \pm 2.6 \%$, by CPCCOEt to $5.9 \pm 1.1 \%$, as well as by MCPG to $30.9 \pm 4.8 \%$ as compared

18 to the control $(100 \%)$.

19 We also generated a pharmacological profile of purinoceptors in OECs. Application of ATP

20 and ADP, but not of UTP, UDP and IDP elicited calcium signaling in outer OECs (Fig. 2D).

21 Inner OECs did not respond to either of the purinoceptor ligands. ATP- and ADP-evoked

22 calcium signaling in outer OECs was greatly reduced by the $\mathrm{P}_{2} \mathrm{Y}_{1}$-selective antagonist

23 MRS2179 to $11.1 \pm 2.5 \%$ of the control (Fig. 2E), and by the P2 receptor antagonist PPADS

24 to $5.2 \pm 4.4 \%$ of the control, while the $\mathrm{P}_{2} \mathrm{Y}_{12}$-specific antagonist ARC69931MX had no effect

25 (Fig. 2F). To test whether neurotransmitter-induced calcium transients in OECs could be

26 mediated by indirect effects by neurotransmitter-dependent neuronal activity, we also applied 
1 receptor ligands to cultured OECs. Cultures of OECs purified from the nerve fibre layer had a

2 purity of over $90 \%$ and were immunopositive for S100ß and p75NTR which are markers of

3 OECs from the outer nerve fibre layer (Windus et al., 2007, Windus et al., 2010). We did not

4 detect OECs that were DsRed-positive, but negative for p75 immunostaining, which would

5 indicate that they are OECs from the inner nerve fibre layer (not shown). Hence, the cultures

6 of OECs had a phenotype of outer OECs. In addition, application of ATP and ADP evoked

7 calcium transients in all cultured OECs investigated, in line with a phenotype of OECs of the

8 outer nerve layer (Fig. 2G). Since other neurotransmitters besides glutamate and ATP exist in

9 the olfactory bulb (Shipley et al., 2004), we tested the effect of some canonical

10 neurotransmitters on cultured OECs and OECs in brain slices (P1-P8). Cultured OECs as well

11 as outer OECs, but not inner OECs, responded to glutamate, serotonin, dopamine and

12 phenylephrine (Fig. 2H; Table 1). A complete list of the substances tested on native and

13 cultured OECs, including the mean values of the calcium responses, is given in Table 1 . The

14 results suggest that OECs in the outer nerve layer express $\mathrm{mGluR}_{1}$ (but not $\mathrm{mGluR}_{5}$ ), $\mathrm{P}_{2} \mathrm{Y}_{1}$

15 receptors, 5-HT receptors, dopamine receptors, noradrenalin receptors and muscarinic

16 acetylcholine receptors. Application of adenosine and GABA, however, did not evoke

17 calcium signaling in OECs, in contrast to astrocytes in the olfactory bulb (Doengi et al., 2008;

18 2009). None of the receptor ligands was able to trigger calcium signaling in OECs of the inner

19 nerve layer, indicating substantial differences in transmitter-evoked calcium signaling 20 between inner and outer OECs.

22 Store-operated calcium entry contributes to calcium signaling in OECs

23 We first aimed to test whether calcium release from internal calcium stores mediated by $\operatorname{InsP}_{3}$ 24 receptors is involved in the ATP-evoked calcium signaling in outer OECs. We inhibited $\operatorname{InsP}_{3}$ 25 receptors with $100 \mu \mathrm{M}$ 2-APB (n=36; Fig. 3A) and depleted internal calcium stores with 26 cyclopiazonic acid $(\mathrm{n}=125$; Fig. $3 \mathrm{~B})$. Both, $\mathrm{InsP}_{3}$ receptor inhibition and store depletion, John Wiley 19 Sons, Inc. 
1 resulted in a significant reduction of the amplitude of ATP-evoked calcium transients (both $2 \mathrm{p}<0.005)$, and both effects were not reversible after 20-30 min. To test whether calcium influx

3 from the extracellular space also contributes to calcium transients evoked by ATP, we 4 compared ATP-induced calcium transients measured in the presence and in the absence of 5 external calcium. In calcium-containing saline, application of $100 \mu \mathrm{M}$ ATP for 2 min resulted

6 in a fast transient calcium rise that eventually passed into a plateau, i.e. the response had 7 phasic and tonic characteristics (Fig. 3A). In calcium-free saline, the tonic response 8 disappeared, and the calcium concentration declined to the baseline before ATP was washed 9 out, suggesting a contribution of calcium influx to the late, tonic phase of the calcium 10 response (Fig. 3C, thick line). In astrocytes, store-operated calcium entry (SOCE) has been 11 shown to contribute to the calcium signaling repertoire and could be blocked by SOCE 12 channel blockers 2-APB and BTP2 (Singaravelu et al., 2006). To test the involvement of 13 SOCE in calcium signaling in OECs, we applied ATP in the presence of $20 \mu \mathrm{M} 2-\mathrm{APB}$, a 14 concentration sufficient to block SOCE channels, but not $\mathrm{Ins}_{3}$ receptors, and BTP2 $(20 \mu \mathrm{M})$. 15 Both, 2-APB and BTP2, suppressed the tonic phase of the calcium response (Fig. 3C,E). To 16 quantify the data, we calculated the area under the calcium curve, normalized to the peak 17 amplitude, and found that the effects of calcium withdrawal, 2-APB and BTP2 on ATP18 evoked calcium signaling were highly significant $(\mathrm{p}<0.005)$ (Fig. 3F). The normalized area was reduced to $47.4 \pm 4.5 \%(\mathrm{n}=46)$ by calcium withdrawal, to $52.5 \pm 4.9 \%(\mathrm{n}=54)$ by 2 $20 \mathrm{APB}$, and to $63.6 \pm 6.0 \%(\mathrm{n}=73)$ by BTP-2, with respect to the control $(100 \%)$. The results 21 indicate that ATP initially triggers calcium release from internal stores via $\mathrm{InsP}_{3}$ receptors, 22 which then leads to activation of SOCE channels and thus calcium influx from the 23 extracellular space. 


\section{Development of $m G l u R_{1}$ and $P 2 Y_{1}$ receptor-mediated calcium signaling}

2 Massive receptor axon ingrowth into the olfactory bulb persists after birth and is accompanied

3 by continuous refinement of glomeruli (Bailey et al., 1999). After the first postnatal week, the

4 gross morphology of the nerve layer and glomerular layer is established, but the size of the

5 glomeruli and the olfactory bulb continue to increase until adulthood (Bailey et al., 1999). We

6 were interested whether these developmental changes in morphology are accompanied by

7 changes in calcium signaling in OECs. The amplitude of DHPG-evoked calcium transients in

8 OECs in the outer nerve layer averaged $42.7 \pm 3.8 \% \Delta \mathrm{F}$ in newborn animals $(\mathrm{P} 0-2)$ and

9 steadily decreased to $33.2 \pm 2.8 \% \Delta \mathrm{F}$ at an age of $\mathrm{P} 3-5$, to $18.9 \pm 2.3 \% \Delta \mathrm{F}$ at $\mathrm{P} 6-8$, and finally

10 to $11.3 \pm 1.4 \% \Delta \mathrm{F}$ in animals older than P13 (Fig. 4A). The decline in the response amplitude

11 from one age to the next was significant in all cases $(p<0.05)$ (Fig. 4B). The decrease in

12 calcium signaling could be due to a decrease in receptor density, or to a modification of the

13 intracellular signaling cascade leading to DHPG-triggered calcium release. We tested the

14 expression of $\mathrm{mGluR}_{1}$ using an anti-mGluR $\mathrm{R}_{1}$ antibody in brain slices of different ages.

15 mGluR1-immunoreactivity was co-localized with P75-immunoreactivity, indicating that

16 mGluR1 was expressed by OECs in the outer nerve layer (Fig. 4C). For the first postnatal

17 days (P0-2), prominent $\mathrm{mGluR}_{1}$-like immunoreactivity was detected in the outer nerve layer,

18 in addition to an intense labeling in the glomerular layer which has been documented before

19 (Martin et al., 1992; Fig. 4C). In the inner nerve layer, however, no immunolabeling above

20 background level could be detected. The intensity of the immunoreactivity in the outer nerve

21 layer was still clearly detectable at P3-5, and then decreased until P6-8. MGluR ${ }_{1}-$ like

22 immunoreactivity was under the detection limit at ages older then $\mathrm{P} 13$, while $\mathrm{mGluR}_{1}$ -

23 immunoreactivity was still visible in the glomerular layer, which served as a control for 24 positive antibody staining (Fig. 4D). These results suggest that a decrease in mGluR 25 expression is responsible for the decrease in amplitude of DHPG-evoked calcium signaling in 26 outer OECs.

John Wiley ${ }^{12}$ Sons, Inc. 
1 Measurements using ATP to stimulate $\mathrm{P}_{2} \mathrm{Y}_{1}$ receptors argue against an impairment of the

2 intracellular calcium signaling cascade downstream the receptor, since the amplitude of ATP-

3 evoked calcium signaling did not change significantly during the first postnatal week and

4 amounted to $57.1 \pm 4.3 \% \Delta \mathrm{F}$ at $\mathrm{P} 0-2,61.0 \pm 4.1 \% \Delta \mathrm{F}$ at $\mathrm{P} 3-5$, and $59.8 \pm 3.6 \% \Delta \mathrm{F}$ at $\mathrm{P} 6-8$

5 (Fig. 4E). The amplitude then decreased significantly to $28.7 \pm 1.8 \% \Delta \mathrm{F}$ until P14-20

$6 \quad(p<0.005$; Fig. 4F). Developmental profiles of other neurotransmitters were not established.

8 Developmental changes of axon stimulation-induced calcium signaling in OECs

9 Electrical stimulation of the olfactory nerve layer triggers vesicular release of glutamate and 10 ATP from receptor axons, which results in calcium signaling in OECs (Thyssen et al., 2010).

11 We used in toto preparations of the olfactory bulb to clarify if OEC calcium signaling 12 following axonal stimulation is subpopulation-specific. Cells were loaded with Fluo-4, and 13 axons were stimulated with a stimulation pipette inserted into the nerve layer (Fig. 5A).

14 Focussing approximately $50-70 \mu \mathrm{m}$ into the tissue, until the first glomeruli appeared as dark

15 regions lacking Fluo-4-labelled cell bodies, we were able to record simultaneously from the 16 outer nerve layer, the inner nerve layer, and the glomerular layer (Fig. 5B). Electrical 17 stimulation of axons for $3 \mathrm{~s}$ at $20 \mathrm{~Hz}(30 \mathrm{~V})$ resulted in calcium transients in OECs of the 18 outer nerve layer, whereas OECs in the inner nerve layer did not respond to axonal 19 stimulation (Fig. 5C). Electrical stimulation triggered calcium signaling also in 20 juxtaglomerular astrocytes and neurons (Fig. 5C, ROI 3), indicating that the lack of 21 responsiveness in inner OECs is not a result of failure of action potential propagation into 22 deeper layers of the olfactory bulb.

23 In mice of the first postnatal week, calcium signaling in outer OECs upon axonal stimulation 24 was reduced by $53.3 \pm 4.6 \%(\mathrm{n}=49)$ in the presence of the $\mathrm{mGluR}_{1}$ antagonist CPCCOEt, 25 and was entirely blocked when the $\mathrm{P}_{2} \mathrm{Y}_{1}$ receptor blocker MRS 2179 was applied in addition, 26 confirming the activation of $\mathrm{mGluR}_{1}$ and $\mathrm{P}_{2} \mathrm{Y}_{1}$ receptors in outer OECs (Fig. 5D). To test John Wiley 13 Sons, Inc. 
1 whether the decrease in $\mathrm{mGluR}_{1}$ and $\mathrm{P}_{2} \mathrm{Y}_{1}$ receptor expression in OECs during postnatal

2 development is reflected by a decrease in stimulation-induced calcium signaling, we evoked 3 calcium signaling in outer OECs of different ages (Fig. 5E). At P0-2, stimulation evoked 4 calcium transients with an amplitude of $133.9 \pm 7.6 \% \Delta \mathrm{F} \quad(\mathrm{n}=208)$. The amplitude 5 significantly increased to $176.1 \pm 8.6 \% \Delta \mathrm{F}(\mathrm{n}=295)$ at $\mathrm{P} 3-5$, but then decreased to $123.3 \pm$ $6 \quad 6.1 \% \Delta \mathrm{F}(\mathrm{n}=304)$ at $\mathrm{P} 6-8$, and to $79.1 \pm 4.7 \% \Delta \mathrm{F}(\mathrm{n}=156)$ at $\mathrm{P} 14-20$, the differences being 7 statistically significant $(p<0.005)$, suggesting that the neurotransmitter-dependent 8 communication between olfactory receptor axons and outer OECs is developmentally 9 regulated (Fig. 5F).

\section{Discussion}

13 As described previously (Au et al., 2002), the labelling pattern of p75NTR, a neurotrophin receptor that is involved in many developmental processes such as neurite outgrowth, differentiation and cell death (Underwood and Coulson, 2008), shows a clear division into two subpopulations of OECs, with OECs only in the outer nerve layer being labelled by the 17 p75NTR antibody. In the present study, we could show that OECs in the outer nerve layer respond to different agonists, such as glutamate, ATP, serotonin, acetylcholine and dopamine

19 with an intracellular calcium increase. In contrast, the OEC population of the inner nerve layer was not immunopositive for p75NTR, and agonist-evoked calcium signals could not be detected. Hence, this is the first study that demonstrates physiological differences between subpopulations of OECs in the olfactory bulb.

Physiological heterogeneity of OECs

25 OECs are considered to promote the growth of olfactory receptor axons that originate in the 26 olfactory epithelium and enter the central nervous system at the level of the olfactory bulb. John Wiley $1 \frac{4}{\&}$ Sons, Inc. 
1 When transplanted into cut nerve ends of dorsal roots or into spinal cord lesions, OECs enable

2 axon growth and functional reconstitution of limb mobility and somatic sensation (Ramon-

3 Cueto \& Nieto-Sampedro 1994, Li et al., 1997). In some studies, however, transplantation of

4 OECs failed to enhance axon regeneration (Ridell et al., 2004; Gomez et al., 2003; Ramer et

5 al., 2004; Lu et al., 2006). Some of the discrepancies between the different studies could be

6 explained by the usage of different OEC subpopulations for transplantation. Roskams and co-

7 workers, e.g., used OECs from the lamina propria (Ramer et al, 2004; Lu et al., 2006), while

8 Raisman and co-workers as well as Ramon-Cueto and Nieto-Sampedro used OECs from the

9 olfactory nerve and olfactory bulb nerve layer (Li et al., 1997; 1998; Ramon-Cueto \& Nieto-

10 Sampedro, 1994). Recent studies, using magnetic beads and fluorescent activated cell sorting

11 (FACS) to purify P75-positive OECs from different regions of the olfactory pathway,

12 demonstrate differences in gene expression profiles and cell proliferation between OECs of

13 the mucosa (lamina propria) and the olfactory bulb (Guerout et al., 2010; Kueh et al., 2011)

14 and between subpopulations in the olfactory bulb nerve layer (Honoré et al., 2012). Although

15 differences between OEC subpopulations in terms of expression of marker proteins and

16 signaling molecules are well known also from other studies (Au et al., 2002; Windus et al.,

17 2010; Wang et al., 2008; Hisaoka et al., 2004), physiological properties of OEC

18 subpopulations have not been measured and analysed comparatively. Calcium signaling and

19 voltage-dependent membrane currents have been measured in olfactory bulb OECs (Rieger et

20 al., 2007; Rela et al., 2010), but the exact position of the studied cells within the nerve layer

21 has not been addressed in these studies. We found striking differences in the functional

22 expression of neurotransmitter receptors between OECs of the outer and inner nerve layer.

23 While OECs in the outer nerve layer respond to a variety of neurotransmitters, inner OECs

24 were insensitive to these substances, with respect to cytosolic calcium responses. Outer OECs

25 not only responded to transmitters applied via the perfusion system, but also to glutamate and

26 ATP endogenously released from olfactory receptor axons, suggesting that neurotransmitters

John Wiley 15 Sons, Inc. 
1 indeed contribute to the orchestration of axon-OEC interactions (Rieger et al., 2007; Thyssen

2 et al., 2010). In particular ATP could be an important messenger in communication between

3 regenerating axons and transplanted OECs in traumatic spinal cord, since ATP is not only a

4 neurotransmitter, but also a mediator of tissue damage and inflammation (Burnstock, 2009).

5 In addition, other neuromodulators shown to affect calcium signaling in OECs might

6 influence the regenerative capacity of transplanted OECs in spinal cord lesions.

8 OECs in olfactory bulb development: A role for calcium signaling?

9 In many glial cell types, elevations in intracellular calcium following activation of 10 metabotropic receptors trigger various kinds of responses, e.g. the secretion of transmitter 11 molecules or growth factors (Ramamoorthy and Whim, 2008; Marchaland et al., 2008;

12 Montana et al., 2006) as well as changes in gene expression (Finkbeiner, 1993). An 13 involvement of intracellular calcium signaling in promoting neuronal axonal growth has been 14 observed in OEC-neuron co-culture (Hayat et al., 2003). Furthermore, there is evidence that 15 secretion of neuroactive substances like BDNF, NGF and neuregulin is employed in OEC 16 interactions with neuronal processes (Pastrana et al., 2007, Boruch et al., 2001), emphasizing 17 their role in axon regeneration. However, the mechanisms by which OECs are activated to 18 interact with axons are not yet elucidated, and calcium signaling is one likely candidate to 19 translate stimulation of OECs into OEC-to-axon communication.

20 In the present study, we could show calcium signaling in OECs mediated by glutamate, the 21 principle neurotransmitter released by ORN (Berkovizc et al., 1994). The pharmacological 22 profile suggests the involvement of $\mathrm{mGluR}_{1}$, since the agonist of mGluR subgroup I 23 (comprising mGluR $_{1}$ and mGluR5), DHPG, evoked calcium signals in OECS, but not the 24 mGluR5 agonist, CHPG. The lack of effect of CHPG is in line with the lack of mGluR5-like 25 immunoreactivity in the olfactory nerve layer (Romano et al., 1995, Sahara et al., 2001). 
1 On the other hand, metabotropic purinergic receptors could evoke intracellular calcium

2 release in this study, too. The involvement of purinergic signaling in addition to the main

3 transmitter in a neuron-glia or glia-glia communication is common in the nervous system and

4 sensory organs (Franke et al., 2006; Housley et al., 2009) and already been described for

5 glomerular astrocytes in the olfactory bulb (Doengi et al., 2008). In OECs, P2 $\mathrm{Y}_{1}$ receptors

6 appear to mediate ATP-induced calcium signaling, since agonists of other P2Y subtypes such

7 as UTP, UDP and IDP were not effective in triggering calcium signals, and the specific

8 antagonist MRS2179 inhibited ADP-induced calcium signals effectively. These results are in

9 accordance with studies from Simon et al. (1997), where the presence of $\mathrm{P} 2 \mathrm{Y}_{1}$ in the nerve layer could be shown with radioactive ligand binding. In the nerve layer, the source for released ATP and glutamate has been shown to be of axonal vesicular origin (Thyssen et al.,

12 2010), presumably acting as an extracellular signaling molecule of ingrowing axons to the 13 OECs, thereupon triggering attraction or repulsion of axons.

14 Purinergic signaling is an important component of nervous system development 15 (Zimmermann, 2011). Metabotropic purinergic receptors are strongly regulated during 16 ontogenesis in the central nervous system (Cheung et al., 2003), and their influence on eye 17 development has been described (Masse et al., 2007). A significant role for $\mathrm{P}_{2} \mathrm{Y}_{1}$ in the development of radial glial cells and neurons could be shown in the subventricular zone, where proliferation of glial cells and migration of neuronal progenitors depends on ATPmediated calcium signals (Weissman et al., 2004; Liu et al., 2008). In addition, neuronal

21 activity evokes calcium signaling in glial cells in the insect olfactory nerve and the olfactory 22 lobe (homologous to the vertebrate olfactory bulb) (Hartl et al., 2007; Heil et al., 2007), and this calcium signaling is required for glial cell migration in these structures (Lohr et al., 2005;

24 Koussa et al., 2011). A similar function of $\mathrm{mGluR}_{1}$ and $\mathrm{P}_{2} \mathrm{Y}_{1}$ receptor-mediated calcium 25 signaling for migration of OECs from the olfactory placode to the telencephalon, a key step in 26 early development of the olfactory system in mammals (Ekberg et al., 2012), could be 
1 speculated, but needs further investigation. The up-regulation of stimulation-evoked calcium

2 signaling in OECs during the first postnatal days, when a large number of receptor axons is

3 still growing into the olfactory bulb, and the down-regulation of mGluR expression and

4 neurotransmitter-evoked calcium signaling during the second to third postnatal week, after

5 which the gross morphological development of the olfactory bulb is completed, supports the

6 hypothesis that calcium signaling is of particular interest for the development of OECs and

7 the nerve layer.

8

\section{Acknowledgements}

10 We thank Jennifer Müller for technical assistance. Financial support by the Deutsche

11 Forschungsgemeinschaft (LO 779/3 and GRK 845) is gratefully acknowledged.

12

13

14

John Wiley 18 Sons, Inc. 


\section{References}

2 Au WW, Treloar HB, Greer CA. 2002. Sublaminar organization of the mouse olfactory bulb 3 nerve layer. J Comp Neurol 446:68-80.

4

5

Bailey MS, Puche AC, Shipley MT. 1999: Development of the olfactory bulb: evidence for glia-neuron interactions in glomerular formation. J Comp Neurol. 415:423-448.

Barnett SC, Riddell JS. 2007. Olfactory ensheathing cell transplantation as a strategy for spinal cord repair--what can it achieve? Nat Clin Pract Neurol. 3:152-161.

Berkowicz DA, Trombley PQ, Shepherd GM. 1994 Evidence for glutamate as the olfactory receptor cell neurotransmitter. J Neurophysiol 71:2557-2561.

Boruch AV, Conners JJ, Pipitone M, Deadwyler G, Storer PD, Devries GH, Jones KJ. 2001. Neurotrophic and migratory properties of an olfactory ensheathing cell line. Glia $33: 225-229$.

Burnstock G. 2009. Purines and sensory nerves. Handb Exp Pharmacol 194:333-392.

Cheung KK, Ryten M, Burnstock G. 2003. Abundant and dynamic expression of G proteincoupled P2Y receptors in mammalian development. Dev Dyn 228:254-266.

Doengi M, Deitmer JW, Lohr C. 2008. New evidence for purinergic signaling in the olfactory bulb: $\mathrm{A} 2 \mathrm{~A}$ and $\mathrm{P} 2 \mathrm{Y} 1$ receptors mediate intracellular calcium release in astrocytes. FASEB J 22:2368-2378.

Doengi M, Hirnet D, Coulon P, Pape HC, Deitmer JW, Lohr C. 2009. GABA uptakedependent $\mathrm{Ca}^{2+}$ signaling in developing olfactory bulb astrocytes. Proc Natl Acad Sci USA 106:17570-17575.

Doucette R. 1990. Glial influences on axonal growth in the primary olfactory system. Glia 3:433-449.

Ekberg JA, Amaya D, Mackay-Sim A, St John JA. 2012. The migration of olfactory ensheathing cells during development and regeneration. Neurosignals. (DOI: $10.1159 / 000330895)$

John Wiley 19 Sons, Inc. 
1 Finkbeiner SM. 1993. Glial calcium. Glia 9:83-104.

2 Fletcher ML, Chen WR. 2010. Neural correlates of olfactory learning: Critical role of 3 centrifugal neuromodulation. Learn Mem 17:561-570.

4 Franke H, Krügel U, Illes P. 2006. P2 receptors and neuronal injury. Pflugers Arch 452:622-

5 644.

Goméz VM, Averill S, King V, Yang Q, Doncel Pérez E, Chacón SC, Ward R, NietoSampedro M, Priestley J, Taylor J. 2003. Transplantation of olfactory ensheathing cells fails to promote significant axonal regeneration from dorsal roots into the rat cervical cord. J Neurocytol 32:53-70.

Guérout N, Derambure C, Drouot L, Bon-Mardion N, Duclos C, Boyer O, Marie J-P. 2010. Comparative gene expression profiling of olfactory ensheathing cells from olfactory bulb and olfactory mucosa. Glia 58:1570-1580.

Hartl S, Heil J, Hirsekorn A, Lohr C. 2007. A novel neurotransmitter-independent communication pathway between axons and glial cells. Eur J Neurosci. 25:945-956.

Hayat S, Wigley CB, Robbins J. 2003. Intracellular calcium handling in rat olfactory ensheathing cells and its role in axonal regeneration. Mol Cell Neurosci 22:259-270.

Heil J, Oland LA, Lohr C. 2007. Acetylcholine-mediated axon-glia signaling in the developing insect olfactory system. Eur J Neurosci. 26:1227-1241.

Hisaoka T, Morikawa Y, Kitamura T, Senba E. 2004. Expression of a member of tumor necrosis factor receptor superfamily, TROY, in the developing olfactory system. Glia 45:313-324.

Honoré A, Le Corre S, Derambure C, Normand R, Duclos C, Boyer O, Marie JP, Guérout N. 2012. Isolation, characterization, and genetic profiling of subpopulations of olfactory ensheathing cells from the olfactory bulb. Glia 60:404-413.

Housley GD, Bringmann A, Reichenbach A. 2009. Purinergic signaling in special senses. Trends Neurosci 32:128-141. 
1 Koussa MA, Tolbert LP, Oland LA. 2011. Development of a glial network in the olfactory

2

3

4 nerve: role of calcium and neuronal activity. Neuron Glia Biol. 6:245-261.

Kueh JL, Raisman G, Li Y, Stevens R, Li D. 2011. Comparison of bulbar and mucosal olfactory ensheathing cells using FACS and simultaneous antigenic bivariate cell cycle analysis. Glia 59:1658-1671.

Li Y, Field PM, Raisman G. 1997. Repair of adult rat corticospinal tract by transplants of olfactory ensheathing cells. Science 277:2000-2002.

Li Y, Field PM, Raisman G. 1998. Regeneration of adult rat corticospinal axons induced by transplanted olfactory ensheathing cells. J Neurosci 18:10514-10524.

Liu X, Hashimoto-Torii K, Torii M, Haydar TF, Rakic P. 2008. The role of ATP signaling in the migration of intermediate neuronal progenitors to the neocortical subventricular zone. Proc Natl Acad Sci U S A 105:11802-11807.

Lohr C, Heil JE, Deitmer JW. 2005. Blockage of voltage-gated calcium signaling impairs migration of glial cells in vivo. Glia 50:198-211.

Lu P, Yang H, Culbertson M, Graham L, Roskams AJ, Tuszynski MH. 2006. Olfactory ensheathing cells do not exhibit unique migratory or axonal growth-promoting properties after spinal cord injury. J Neurosci 26:11120-11130.

Masse K, Bhamra S, Eason R, Dale N, Jones EA. 2007. Purine-mediated signalling triggers eye development. Nature 449:1058-1062.

Marchaland J, Calì C, Voglmaier SM, Li H, Regazzi R, Edwards RH, Bezzi P. 2008. Fast subplasma membrane $\mathrm{Ca}^{2+}$ transients control exo-endocytosis of synaptic-like microvesicles in astrocytes. J Neurosci 28:9122-9132.

Martin LJ, Blackstone CD, Huganir RL, Price DL. 1992. Cellular localization of a metabotropic glutamate receptor in rat brain. Neuron 9:259-270.

Montana V, Malarkey EB, Verderio C, Matteoli M, Parpura V. 2006. Vesicular transmitter release from astrocytes. Glia 54:700-715. 
1 Pastrana E, Moreno-Flores MT, Avila J, Wandosell F, Minichiello L, Diaz-Nido J. 2007. BDNF production by olfactory ensheathing cells contributes to axonal regeneration of cultured adult CNS neurons. Neurochem Int 50:491-498.

Raisman G, Li Y. Repair of neural pathways by olfactory ensheathing cells. 2007. Nat Rev Neurosci 8:312-319.

Ramamoorthy P, Whim MD. 2008. Trafficking and fusion of neuropeptide Y-containing dense-core granules in astrocytes. J Neurosci 28:13815-13827.

Ramer LM, Richter MW, Roskams AJ, Tetzlaff W, Ramer MS. 2004. Peripherally-derived olfactory ensheathing cells do not promote primary afferent regeneration following dorsal root injury. Glia 47:189-206.

Ramon-Cueto A, Nieto-Sampedro M. 1994. Regeneration into the spinal cord of transected dorsal root axons is promoted by ensheathing glia transplants. Exp Neurol 127:232244.

Raponi E, Agenes F, Delphin C, Assard N, Baudier J, Legraverend C, Deloulme JC. 2007. S100B expression defines a state in which GFAP-expressing cells lose their neural stem cell potential and acquire a more mature developmental stage. Glia 55:165-177.

Rela L, Bordey A, Greer CA. 2010. Olfactory ensheathing cell membrane properties are shaped by connectivity. Glia 58:665-678.

Riddell JS, Enriquez-Denton M, Toft A, Fairless R, Barnett SC. 2004. Olfactory ensheathing cell grafts have minimal influence on regeneration at the dorsal root entry zone following rhizotomy. Glia 47:150-167.

Rieger A, Deitmer JW, Lohr C. 2007. Axon-glia communication evokes calcium signaling in olfactory ensheathing cells of the developing olfactory bulb. Glia 55:352-359.

Romano C, Sesma MA, McDonald CT, O'Malley K, Van den Pol AN, Olney JW. 1995. Distribution of metabotropic glutamate receptor mGluR5 immunoreactivity in rat brain. J Comp Neurol 355:455-469. 
1 Sahara Y, Kubota T, Ichikawa M.2001. Cellular localization of metabotropic glutamate

2

3

4 5 receptors mGluR1, 2/3, 5 and 7 in the main and accessory olfactory bulb of the rat Neurosci Lett 312:59-62.

Shipley MT, Ennis M, Puche A. 2004. Olfactory system. In: G. Paxinos, editor. The rat nervous system, third edition. Elsevier Academic Press, London. p. 922-962.

Simon J, Webb TE, Barnard EA. 1997. Distribution of [35S]dATP alpha S binding sites in the adult rat neuraxis. Neuropharmacology 36:1243-1251.

Singaravelu K, Lohr C, Deitmer JW. 2006. Regulation of store-operated calcium entry by calcium-independent phospholipase A2 in rat cerebellar astrocytes. J Neurosci 26:9579-9592.

Stavermann M, Buddrus K, St John JA, Ekberg JAK, Nilius B, Deitmer JW, Lohr C. 2012: Temperature-dependent calcium-induced calcium release via InsP3 receptors in mouse olfactory ensheathing glial cells. Cell Calcium 52:13-23.

Thyssen A, Hirnet D, Wolburg H, Schmalzing G, Deitmer JW, Lohr C. 2010. Ectopic vesicular neurotransmitter release along sensory axons mediates neurovascular coupling via glial calcium signaling. Proc Natl Acad Sci USA 107:15258-15263.

Underwood CK, Coulson EJ. 2008. The P75 neurotrophin receptor. Int J Biochem Cell Biol 40:1664-1668.

Wang YZ, Molotkov A, Song L, Li Y, Pleasure DE, Zhou CJ. 2008. Activation of the Wnt/beta-catenin signaling reporter in developing mouse olfactory nerve layer marks a specialized subgroup of olfactory ensheathing cells. Dev Dyn 237:3157-3168.

Weissman TA, Riquelme PA, Ivic L, Flint AC, Kriegstein AR. 2004. Calcium waves propagate through radial glial cells and modulate proliferation in the developing neocortex. Neuron 43:647-661. 
1 Windus LCE, Claxton C, Allen CL, Key B, St John JA. 2007: Motile membrane protrusions regulate cell-cell adhesion and migration of olfactory ensheathing glia, Glia. 55:1708-

3 1719.

4 Windus LC, Lineburg KE, Scott SE, Claxton C, Mackay-Sim A, Key B, St John JA. 2010.

5 Lamellipodia mediate the heterogeneity of central olfactory ensheathing cell

$6 \quad$ interactions. Cell Mol Life Sci 67:1735-1750.

7 Zimmermann H. 2011. Purinergic signaling in neural development. Sem Cell Dev Biol 8 22:194-204.

John Wiley 24 Sons, Inc. 


\section{Tables}

2

3 Table 1: Efficacy of receptor ligands on cytosolic calcium in OECs (P1-P8) of the outer and

4 inner nerve layer (NL) and in cultured OECs. Values represent mean increases in fluorescence

$5(\Delta \mathrm{F})$, the number in parentheses indicate the number of analyzed cells.

\begin{tabular}{|c|c|c|c|}
\hline $\begin{array}{l}\text { Substance } \\
(100 \mu \mathrm{M})\end{array}$ & $\begin{array}{l}\text { outer } \mathrm{NL} \\
(\Delta \mathrm{F}[\%])\end{array}$ & inner NL & $\begin{array}{c}\text { cultured OECs } \\
(\Delta \mathrm{F}[\%])\end{array}$ \\
\hline Glutamate & $158.1 \pm 1.1(43)$ & - & $27.5 \pm 3.3(38)$ \\
\hline DHPG & $70.4 \pm 1.1(72)$ & - & nd \\
\hline CHPG & - & - & nd \\
\hline ATP & $61.0 \pm 4.1(119)$ & - & $31.7 \pm 5.7(18)$ \\
\hline ADP & $70.4 \pm 5.3(54)$ & - & $59.6 \pm 5.5(31)$ \\
\hline UTP & - & - & nd \\
\hline UDP & - & - & nd \\
\hline IDP & - & - & nd \\
\hline Adenosine & - & - & nd \\
\hline GABA & - & - & nd \\
\hline Dopamine & $42.4 \pm 4.8(33)$ & - & $38.1 \pm 3.9(45)$ \\
\hline Serotonin & $40.8 \pm 3.0(189)$ & - & $78.6 \pm 9.5(75)$ \\
\hline Carbachol & $80.6 \pm 5.6(278)$ & - & nd \\
\hline Phenylephrine & $154.7 \pm 8.1(89)$ & - & $93.1 \pm 18.6(28)$ \\
\hline
\end{tabular}




\section{Figure legends}

2

3 Fig. 1. Morphology of the nerve layer (NL) in the developing mouse olfactory bulb. (A)

4 DsRed expression under control of the S100B promoter (red) and S100 immunoreactivity

5 (green) in the NL. Nuclei were stained with DAPI (blue). Asterisks indicate glomeruli in the

6 glomerular layer (GL). (B) P75NTR-immunoreactivity (green) is only found in the outer

7 nerve layer $\left(\mathrm{NL}_{\mathrm{o}}\right)$, but not in the inner nerve layer $\left(\mathrm{NL}_{\mathrm{i}}\right)$. Red labelling (propidium iodide)

8 indicate nuclei. (C) DiA-labelled receptor axons (green) proceed in straight bundles

9 (arrowhead) in the outer nerve layer, and eventually separate to cross the inner nerve layer (arrows) and enter a glomerulus (asterisk). (D) After loading olfactory bulb slices with Fluo-4 AM, OECs in the outer nerve layer were strongly labelled by Fluo-4, whereas OECs in the inner nerve layer were weaker labelled. Scale bars: $50 \mu \mathrm{m}$.

Fig. 2. Neurotransmitter-evoked calcium signaling in OEC subpopulations. (A) OECs in the outer nerve layer, but not the inner nerve layer, respond to the mGluR agonist DHPG $(20 \mu \mathrm{M})$ with a calcium transient, while the mGluR $_{5}$-specific agonist CHPG $(100 \mu \mathrm{M})$ had no effect on the calcium concentration in either cell type. (B) DHPG-induced calcium transients were reduced by the mGluR $_{1}$-specific antagonists JNJ 16259685, and (C) CPCCOEt. (D) ATP and ADP, but not UTP, UDP and IDP evoke calcium transients in OECs of the outer nerve layer, while purines did not evoke calcium signaling in OECs in the inner nerve layer. (E) Calcium transients evoked by ATP were blocked by the $\mathrm{P}_{2} \mathrm{Y}_{1}$ receptor antagonist MRS 2179. (F) Summary of antagonistic effects of mGluR and P2Y receptor ligands. The $\mathrm{mGluR}_{1}$-specific antagonists JNJ $16259685(10 \mu \mathrm{M})$, YM $230888(1 \mu \mathrm{M})$ and CPCCOEt $(100 \mu \mathrm{M})$ as well as the non-specific mGluR antagonist $(\mathrm{R}, \mathrm{S})-\mathrm{MCPG}(1 \mathrm{mM})$ significantly reduced DHPG-evoked responses in OECs of the outer nerve layer. The non-specific P2 receptor antagonist PPADS $(100 \mu \mathrm{M})$ and the $\mathrm{P}_{2} \mathrm{Y}_{1}$-specific antagonist MRS $2179(60 \mu \mathrm{M})$ reduced ADP/ATP-evoked 
1 calcium transients in OECs in the outer nerve layer, while the $\mathrm{P}_{2} \mathrm{Y}_{12}$-specific antagonist

2 ARC69931MX $(100 \mu \mathrm{M})$ had no effect. ***, $\mathrm{p}<0.005$. (G) In cultured OECs, ATP $(100 \mu \mathrm{M})$

3 and $\operatorname{ADP}(100 \mu \mathrm{M})$, as well as serotonin $(100 \mu \mathrm{M})(\mathbf{H})$ elicit calcium transients.

4

5 Fig. 3. Calcium stores and store-operated calcium entry in OECs of the outer nerve layer. (A)

6 Calcium transients evoked by ATP $(100 \mu \mathrm{M}, 1 \mathrm{~min})$ were reduced in amplitude in the 7 presence of $100 \mu \mathrm{M}$ 2-APB, which blocks $\operatorname{InsP}_{3}$ receptor at that concentration. (B) Depletion 8 of calcium stores with $20 \mu \mathrm{M}$ cyclopiazonic acid (CPA) suppressed ATP-induced calcium 9 transients. (C) Application of ATP $(100 \mu \mathrm{M})$ for 2 minutes evoked a fast calcium peak, 10 followed by a tonic calcium elevation that continued for at least the time of application (thin 11 trace). In the absence of external calcium $\left(0 \mathrm{Ca}^{2+}\right)$, the tonic phase was suppressed, and the 12 calcium transient returned to the baseline value during ATP application (thick trace). Traces 13 were normalized to the peak amplitude to accomplish comparability. (D) $20 \mu \mathrm{M} 2$ 2-APB, 14 which is sufficient to block store-operated calcium channels but not $\mathrm{InsP}_{3}$ receptors, and 20 $15 \mu \mathrm{M}$ BTP2 (E) suppressed the tonic phase of the ATP-induced calcium response. (F) The 16 integral of the normalized calcium response, reflecting both the fast calcium peak mediated by 17 intracellular calcium release and the tonic phase reflecting calcium influx, decreased in the absence of external calcium, and in the presence of 2-APB and BTP2. ***, $<<0.005$.

Fig. 4. Development of DHPG- and ATP-evoked calcium signaling in OECs of the outer nerve layer. (A) The amplitude of DHPG-evoked calcium transients steadily decreased during the first postnatal weeks. (B) Differences in amplitude of DHPG-evoked calcium transients in 23 OECs in four age groups, postnatal days 0-2 (P0-2), P3-5, $\mathrm{P} 6-8$ and older than $\mathrm{P} 13$, were 24 significantly different as compared to the neighboring age groups. ${ }^{*}, \mathrm{p}<0.05 ; * *, \mathrm{p}<0.01 ; * * *$, $25 \mathrm{p}<0.005$. (C) Anti-mGluR 1 immunostaining (green) co-localizes with anti-P75 26 immunoreactivity (red) in the nerve layer of an olfactory bulb slice of an animal at P1. OECs 
1 in the outer nerve layer (arrowhead) as well as glomeruli (asterisks) are mGluR1-

2 immunopositive. (D) Decreasing number of $\mathrm{mGluR}_{1}$-positive OECs (arrowheads) from P4 to

$3 \quad$ P7 and P16, while the staining in glomeruli remained intense (asterisks). Cell nuclei were

4 stained with propidium iodide (red). (E) ATP-evoked calcium transients in OECs of different

5 ages. (F) The amplitude of ATP-evoked calcium transients remained constant from P0 to P8,

6 and then decreased between P8 and P14 and older. Scale bars: $20 \mu \mathrm{m}(\mathrm{C}), 50 \mu \mathrm{m}$ (D).

8 Fig. 5. Development of stimulation-induced calcium transients in OECs in olfactory bulbs in

9 toto. (A) Experimental setup. (B) Original confocal image of the olfactory bulb in which the traces in the regions of interest $(1,23)$ in $(\mathbf{C})$ were recorded. Glomeruli are asterisked to 11 indicate the glomerular layer (GL). The arrowhead highlights the stimulation pipette. (C) 12 Calcium transients could be evoked by electrical stimulation $(20 \mathrm{~Hz}, 3 \mathrm{~s})$ of receptor axons in OECs of the outer nerve layer (ROI 1) and periglomerular astrocytes (ROI 3), but not in

14 OECs of the inner nerve layer (ROI 2). (D) Stimulation-induced calcium transients in OECs 15 of the outer nerve layer were inhibited by combination of CPCCOEt $(100 \mu \mathrm{M})$ and MRS 2179 $16(60 \mu \mathrm{M})$. (E) Stimulation-induced calcium transients at different ages. (F) The amplitude of stimulation-evoked calcium transients in OECs of the outer nerve layer increased significantly from birth to P3-P5, and then steadily decreased until P14 and older. ***, $\mathrm{p}<0.005$.

Supplementary figure 1. Photolysis of caged $\mathrm{InsP}_{3}$ and application of cyclopiazonic acid evoke calcium signaling in OECs in the inner nerve layer. (A) OECs were bulk-loaded by injecting $40 \mu \mathrm{M}$ of the membrane-permeant ci-Ins $\mathrm{P}_{3} / \mathrm{PM}$ (caged $\operatorname{Ins}_{3}$ ) together with $200 \mu \mathrm{M}$ Fluo-4 AM into the tissue. After 30-60 min, during which OECs took up both caged $\operatorname{InsP}_{3}$ and 24 Fluo-4, OECs were illuminated with a $405 \mathrm{~nm}$ laser diode for 2 seconds, which resulted in an 25 immediate calcium response of $185.1 \pm 22.4 \Delta \mathrm{F}$ (60 cells from 6 preparations derived from 3 26 animals). (B) Depletion of internal calcium stores by cyclopiazonic acid (CPA) is reflected by 
1 a transient increase in cytosolic calcium of $64.3 \pm 3.6 \% \Delta \mathrm{F}(\mathrm{n}=59)$ in OECs of the inner nerve 2 layer. The traces represent individual OECs.

John Wiley 29 Sons, Inc. 

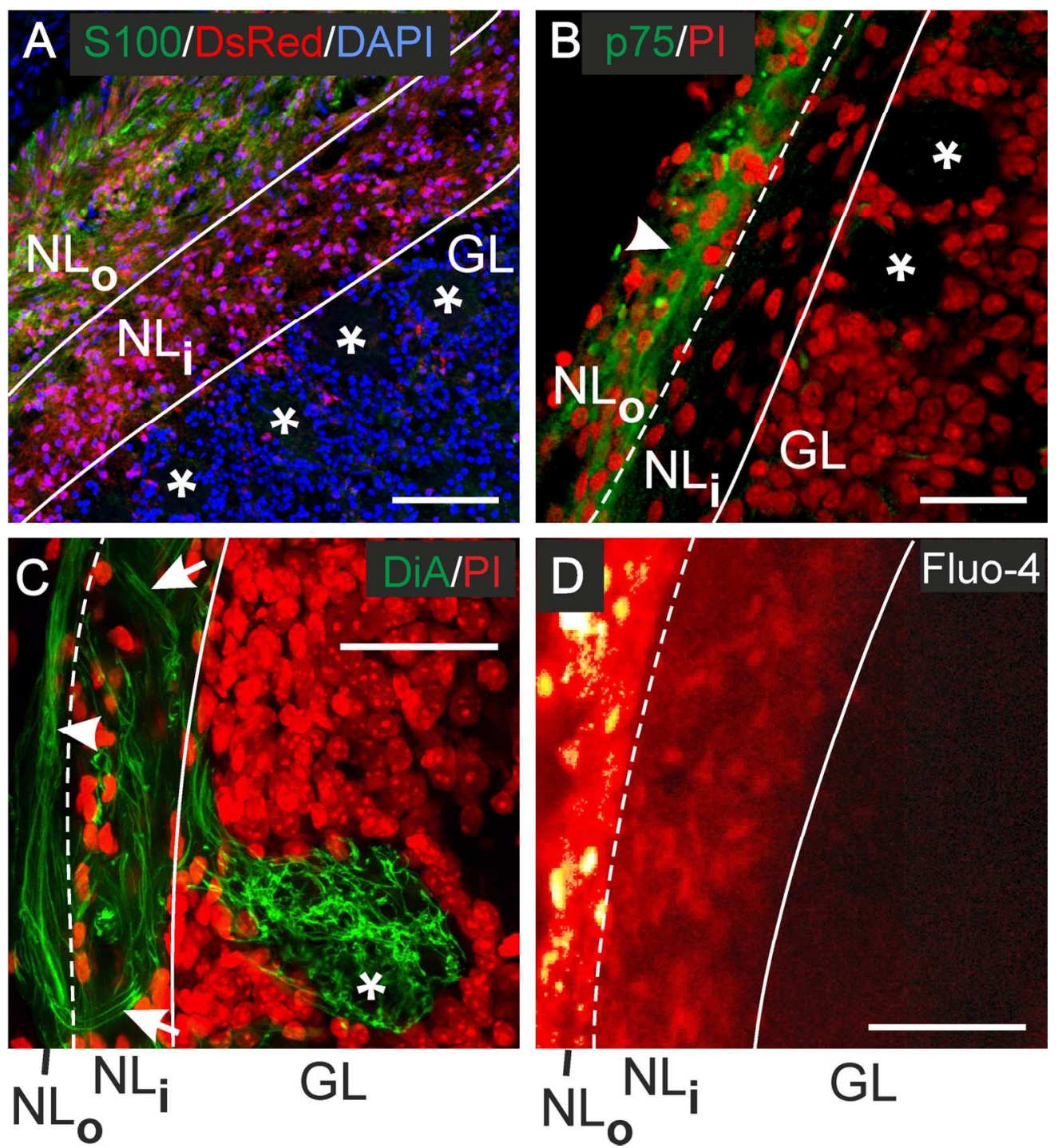

Fig. 1. Morphology of the nerve layer (NL) in the developing mouse olfactory bulb. (A) DsRed expression under control of the S100B promoter (red) and S100 immunoreactivity (green) in the NL. Nuclei were stained with DAPI (blue). Asterisks indicate glomeruli in the glomerular layer (GL). (B) P75NTR-

immunoreactivity (green) is only found in the outer nerve layer (NLo), but not in the inner nerve layer (NLi). Red labelling (propidium iodide) indicate nuclei. (C) DiA-labelled receptor axons (green) proceed in straight bundles (arrowhead) in the outer nerve layer, and eventually separate to cross the inner nerve layer (arrows) and enter a glomerulus (asterisk). (D) After loading olfactory bulb slices with Fluo-4 AM, OECs in the outer nerve layer were strongly labelled by Fluo-4, whereas OECs in the inner nerve layer were weaker labelled. Scale bars: $50 \mu \mathrm{m}$. $132 \times 144 \mathrm{~mm}(300 \times 300 \mathrm{DPI})$ 

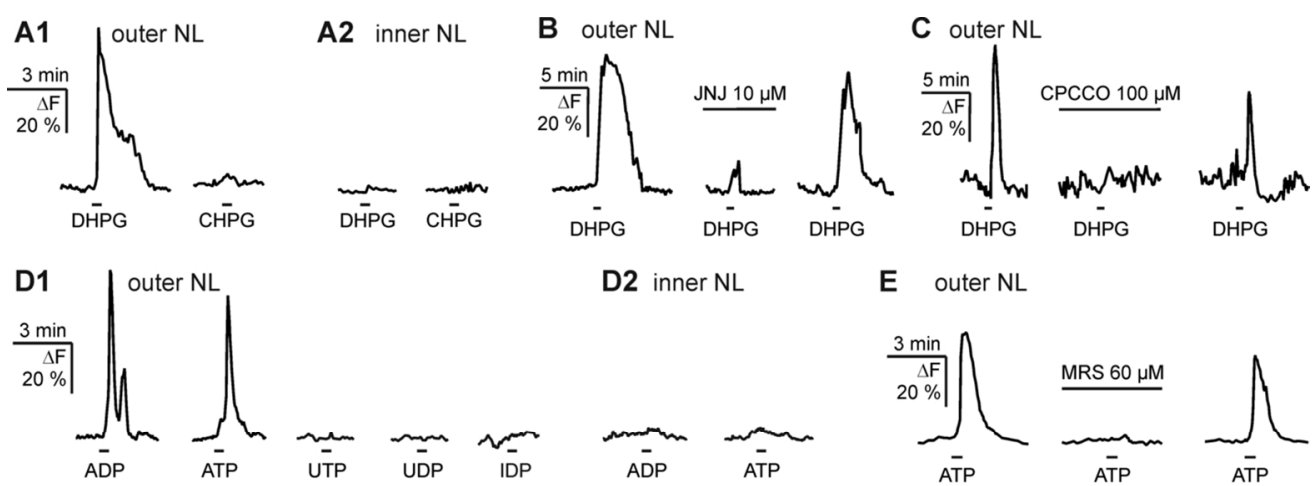

D2 inner NL

E outer NL
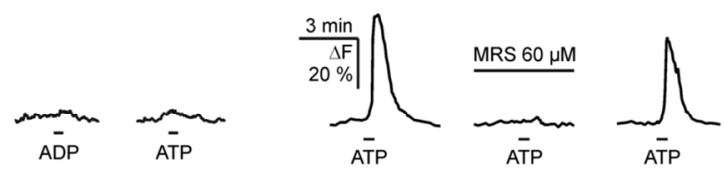

$\mathbf{F}$

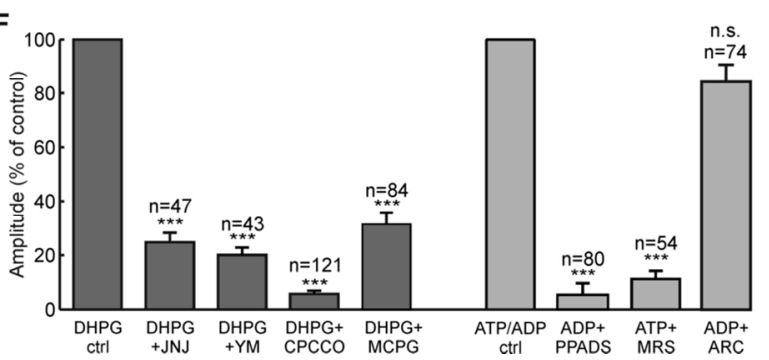

G cultured OECs

H cultured OECs
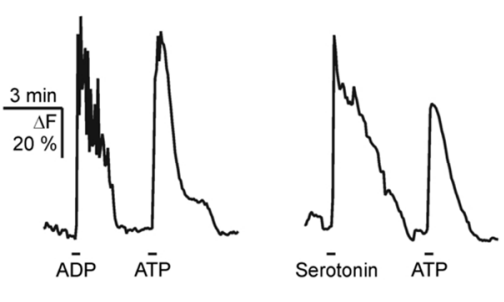

Fig. 2. Neurotransmitter-evoked calcium signaling in OEC subpopulations. (A) OECs in the outer nerve layer, but not the inner nerve layer, respond to the mGluR agonist DHPG $(20 \mu \mathrm{M})$ with a calcium transient, while the mGluR5-specific agonist CHPG $(100 \mu \mathrm{M})$ had no effect on the calcium concentration in either cell type.

(B) DHPG-induced calcium transients were reduced by the mGluR1-specific antagonists JNJ 16259685, and (C) CPCCOEt. (D) ATP and ADP, but not UTP, UDP and IDP evoke calcium transients in OECs of the outer nerve layer, while purines did not evoke calcium signaling in OECs in the inner nerve layer. (E) Calcium transients evoked by ATP were blocked by the P2Y1 receptor antagonist MRS 2179. (F) Summary of antagonistic effects of mGluR and P2Y receptor ligands. The mGluR1-specific antagonists JNJ 16259685 (10 $\mu \mathrm{M})$, YM $230888(1 \mu \mathrm{M})$ and CPCCOEt $(100 \mu \mathrm{M})$ as well as the non-specific mGluR antagonist (R,S)-MCPG $(1$ $\mathrm{mM}$ ) significantly reduced DHPG-evoked responses in OECs of the outer nerve layer. The non-specific P2 receptor antagonist PPADS $(100 \mu \mathrm{M})$ and the P2Y1-specific antagonist MRS $2179(60 \mu \mathrm{M})$ reduced ADP/ATPevoked calcium transients in OECs in the outer nerve layer, while the P2Y12-specific antagonist ARC69931MX $(100 \mu \mathrm{M})$ had no effect. ***, $\mathrm{p}<0.005$. (G) In cultured OECs, ATP $(100 \mu \mathrm{M})$ and ADP $(100$ $\mu \mathrm{M})$, as well as serotonin $(100 \mu \mathrm{M})(\mathrm{H})$ elicit calcium transients.

$$
120 \times 76 \mathrm{~mm} \text { (300 x } 300 \text { DPI) }
$$


A Control

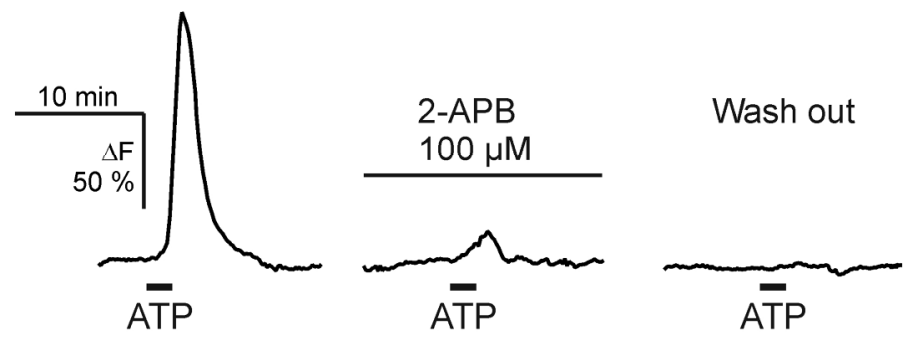

B Control
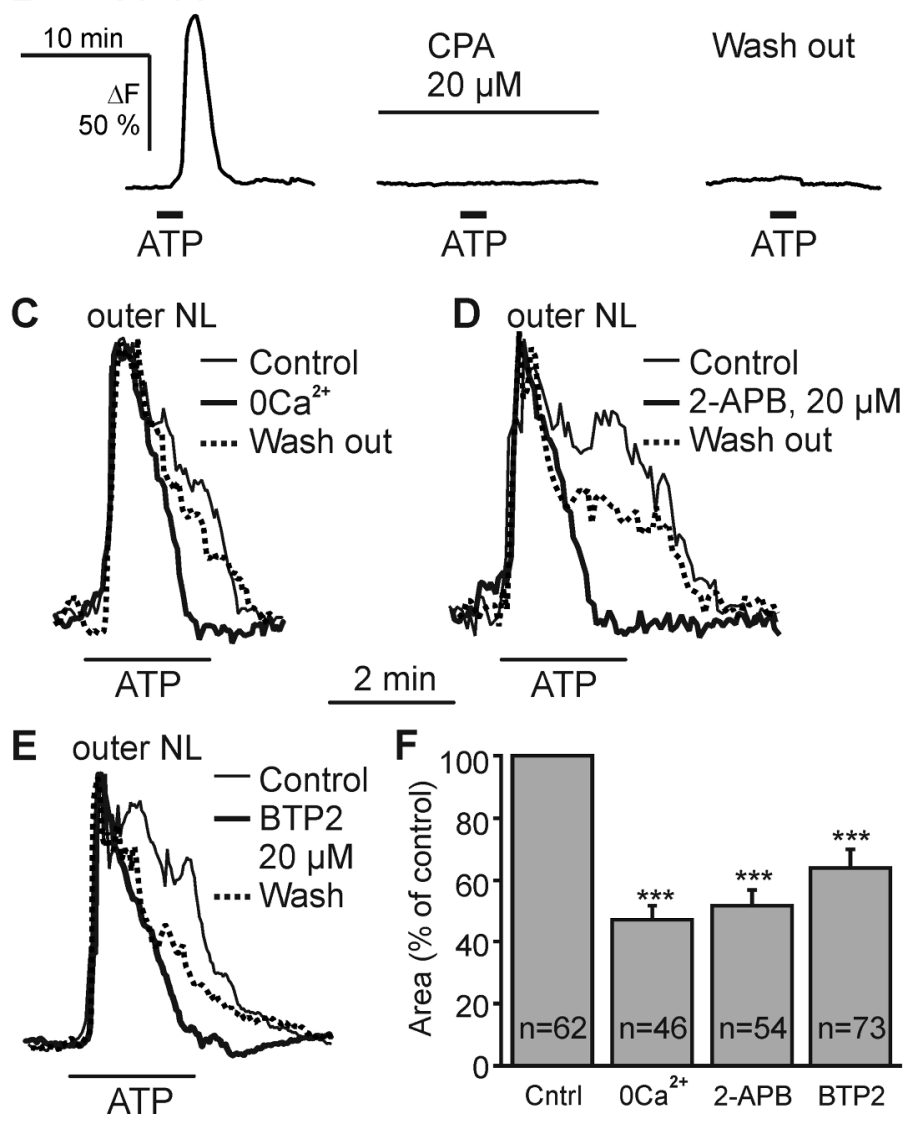

Fig. 3. Calcium stores and store-operated calcium entry in OECs of the outer nerve layer. (A) Calcium transients evoked by ATP $(100 \mu \mathrm{M}, 1 \mathrm{~min})$ were reduced in amplitude in the presence of $100 \mu \mathrm{M} 2-\mathrm{APB}$, which blocks InsP3 receptor at that concentration. (B) Depletion of calcium stores with $20 \mu \mathrm{M}$ cyclopiazonic acid (CPA) suppressed ATP-induced calcium transients. (C) Application of ATP (100 $\mu$ M) for 2 minutes evoked a fast calcium peak, followed by a tonic calcium elevation that continued for at least the time of application (thin trace). In the absence of external calcium (0Ca2+), the tonic phase was suppressed, and the calcium transient returned to the baseline value during ATP application (thick trace). Traces were normalized to the peak amplitude to accomplish comparability. (D) $20 \mu \mathrm{M} 2$-APB, which is sufficient to block store-operated calcium channels but not InsP3 receptors, and $20 \mu \mathrm{M}$ BTP2 (E) suppressed the tonic phase of the ATP-induced calcium response. (F) The integral of the normalized calcium response, reflecting both the fast calcium peak mediated by intracellular calcium release and the tonic phase reflecting calcium influx, decreased in the absence of external calcium, and in the presence of 2-APB and BTP2. $* * *, \mathrm{p}<0.005$.

$161 \times 282 \mathrm{~mm}(300 \times 300 \mathrm{DPI})$ 
John Wiley \& Sons, Inc. 

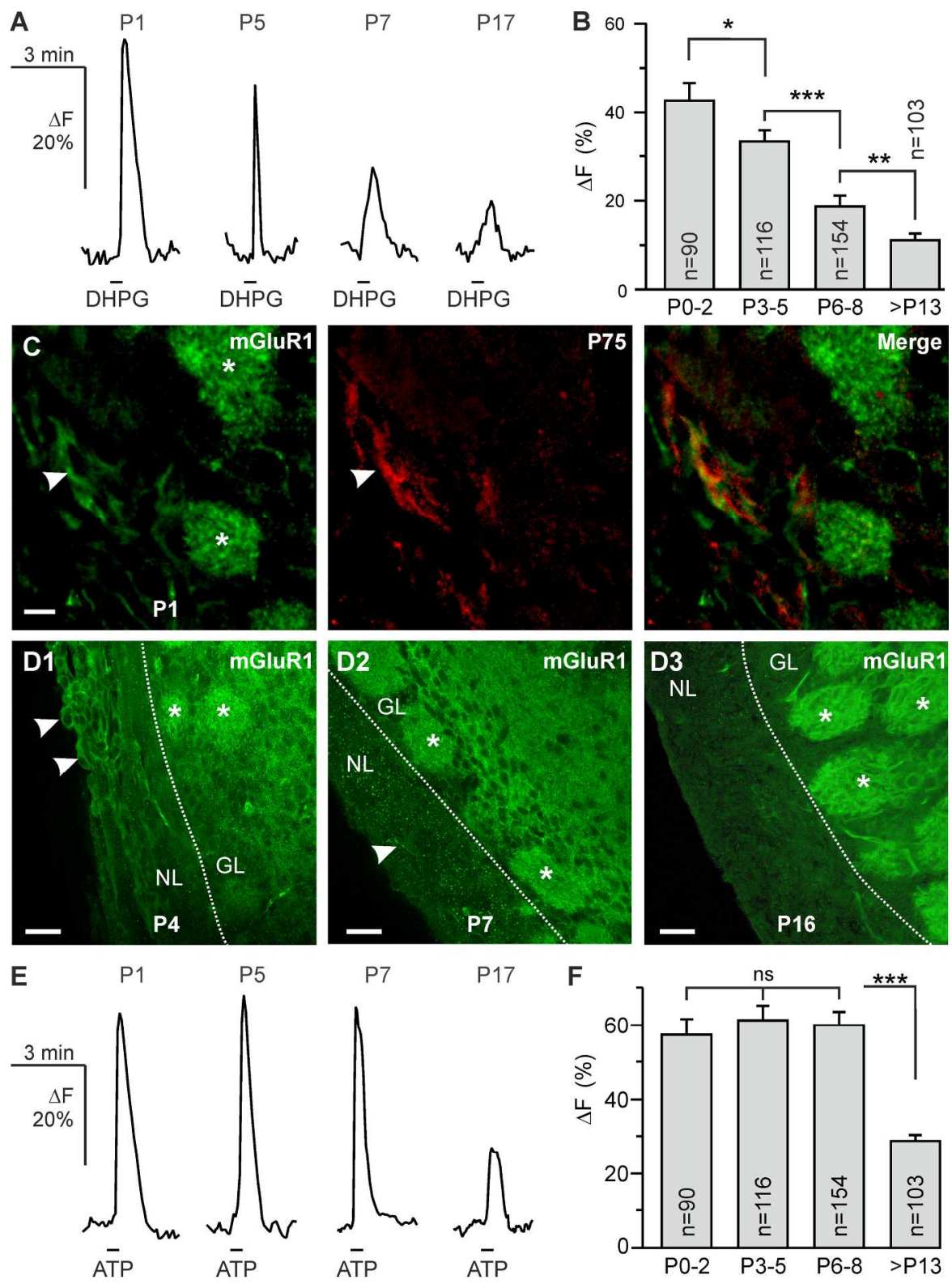

Fig. 4. Development of DHPG- and ATP-evoked calcium signaling in OECs of the outer nerve layer. (A) The amplitude of DHPG-evoked calcium transients steadily decreased during the first postnatal weeks. (B) Differences in amplitude of DHPG-evoked calcium transients in OECs in four age groups, postnatal days 0-2 (P0-2), P3-5, P6-8 and older than P13, were significantly different as compared to the neighboring age groups. *, $\mathrm{p}<0.05 ; * *, \mathrm{p}<0.01 ; * * *, \mathrm{p}<0.005$. (C) Anti-mGluR1 immunostaining (green) co-localizes with anti-P75 immunoreactivity (red) in the nerve layer of an olfactory bulb slice of an animal at P1. OECs in the outer nerve layer (arrowhead) as well as glomeruli (asterisks) are mGluR1-immunopositive. (D) Decreasing number of mGluR1-positive OECs (arrowheads) from P4 to P7 and P16, while the staining in glomeruli remained intense (asterisks). Cell nuclei were stained with propidium iodide (red). (E) ATP-evoked calcium transients in OECs of different ages. (F) The amplitude of ATP-evoked calcium transients remained constant from P0 to P8, and then decreased between P8 and P14 and older. Scale bars: $20 \mu \mathrm{m}$ (C), $50 \mu \mathrm{m}$ (D). $201 \times 271 \mathrm{~mm}(300 \times 300$ DPI $)$ 
John Wiley \& Sons, Inc. 
A

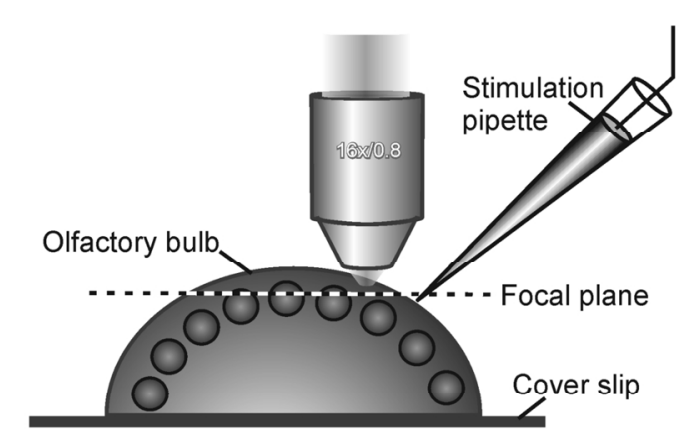

B

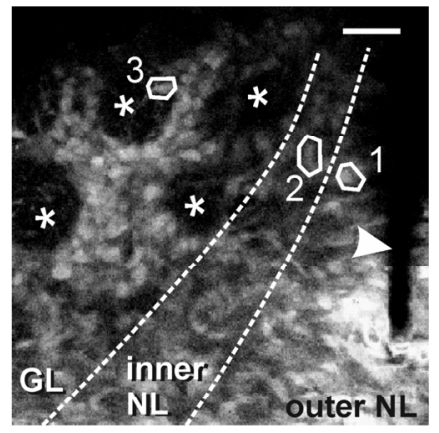

$\begin{array}{lll}\text { C outer NL } & \text { inner NL } & \text { GL, astrocyte } \\ \text { ROI1 } & \text { ROI2 } & \text { ROI3 }\end{array}$

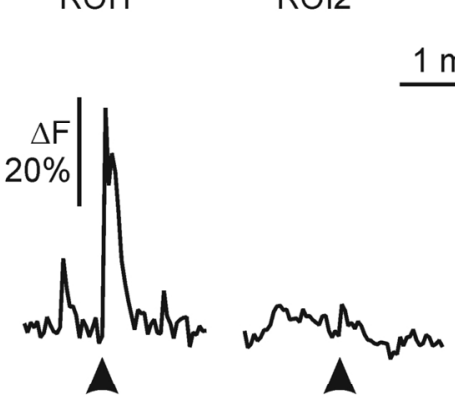

$20 \mathrm{~Hz}, 3 \mathrm{~s}$
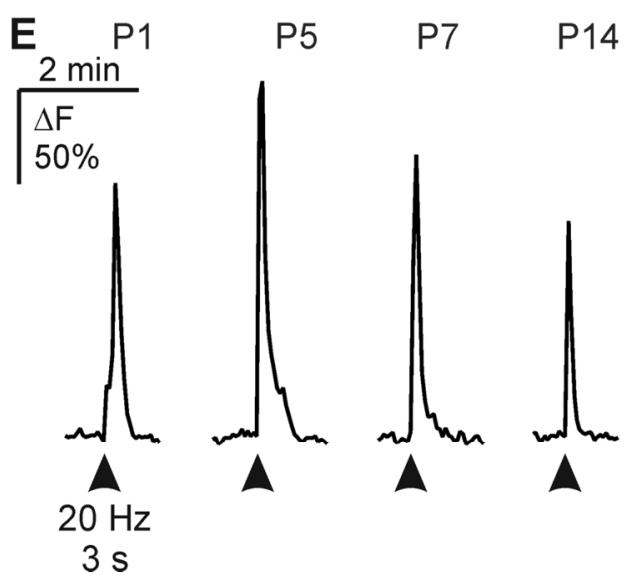
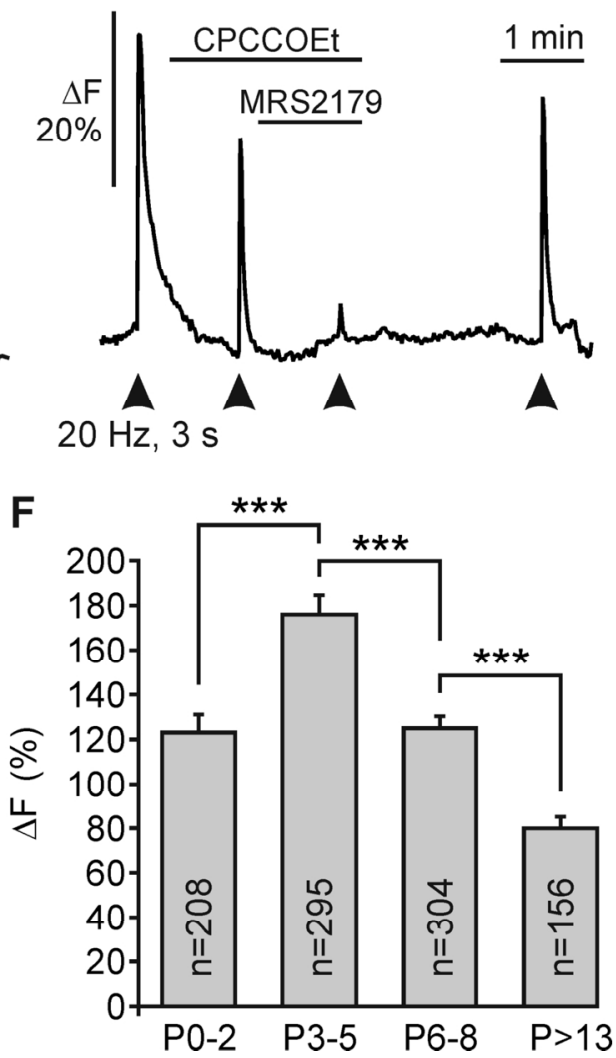

Fig. 5. Development of stimulation-induced calcium transients in OECs in olfactory bulbs in toto. (A) Experimental setup. (B) Original confocal image of the olfactory bulb in which the traces in the regions of interest $(1,23)$ in (C) were recorded. Glomeruli are asterisked to indicate the glomerular layer (GL). The arrowhead highlights the stimulation pipette. (C) Calcium transients could be evoked by electrical stimulation $(20 \mathrm{~Hz}, 3 \mathrm{~s})$ of receptor axons in OECs of the outer nerve layer (ROI 1) and periglomerular astrocytes (ROI 3), but not in OECs of the inner nerve layer (ROI 2). (D) Stimulation-induced calcium transients in OECs of the outer nerve layer were inhibited by combination of CPCCOEt $(100 \mu \mathrm{M})$ and MRS

$2179(60 \mu \mathrm{M})$. (E) Stimulation-induced calcium transients at different ages. (F) The amplitude of stimulation-evoked calcium transients in OECs of the outer nerve layer increased significantly from birth to P3-P5, and then steadily decreased until P14 and older. $* * *, \mathrm{p}<0.005$.

$154 \times 186 \mathrm{~mm}(300 \times 300 \mathrm{DPI})$ 


\section{A OEC in inner nerve layer bulk-loaded with ci-InsP3/PM (caged $\mathrm{IP}_{3}$ ) and Fluo-4 AM}

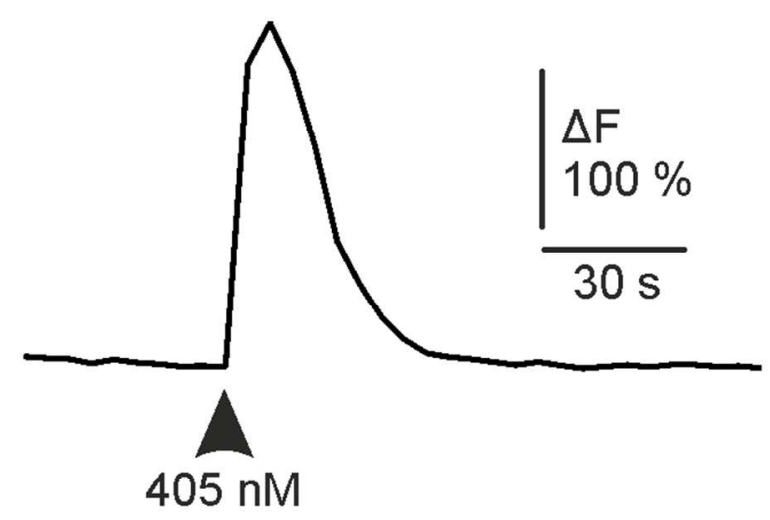

\section{B OEC in inner nerve layer bulk-loaded with Fluo-4 AM}

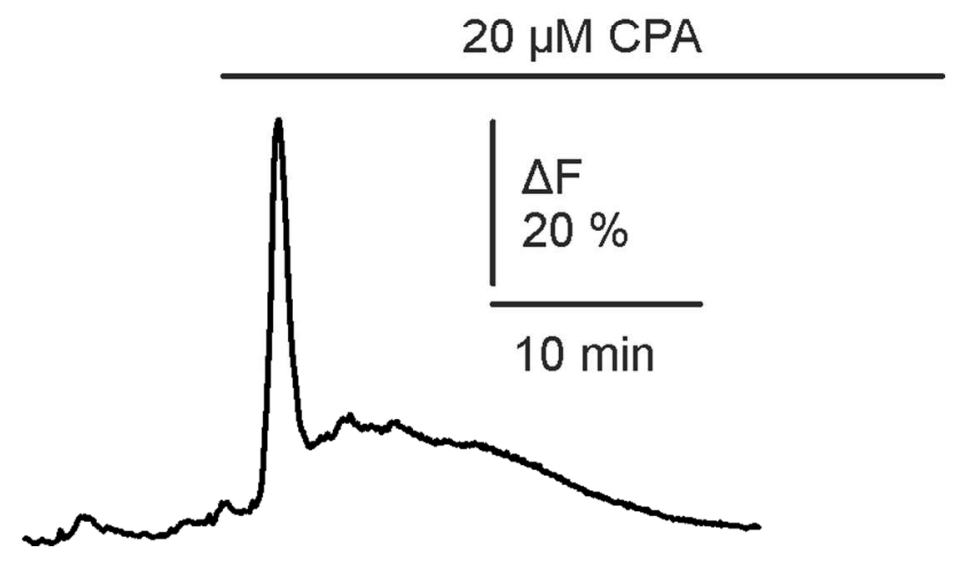

Supplementary figure 1. Photolysis of caged InsP3 and application of cyclopiazonic acid evoke calcium signaling in OECs in the inner nerve layer. (A) OECs were bulk-loaded by injecting $40 \mu \mathrm{M}$ of the membranepermeant ci-InsP3/PM (caged InsP3) together with $200 \mu \mathrm{M}$ Fluo-4 AM into the tissue. After 30-60 min, during which OECs took up both caged InsP3 and Fluo-4, OECs were illuminated with a $405 \mathrm{~nm}$ laser diode

for 2 seconds, which resulted in an immediate calcium response of $185.1 \pm 22.4 \Delta \mathrm{F}$ ( 60 cells from 6 preparations derived from 3 animals). (B) Depletion of internal calcium stores by cyclopiazonic acid (CPA) is reflected by a transient increase in cytosolic calcium of $64.3 \pm 3.6 \% \Delta F(n=59)$ in OECs of the inner nerve

layer. The traces represent individual OECs.

$$
75 \times 115 \mathrm{~mm}(300 \times 300 \mathrm{DPI})
$$

